\title{
TECNOLOGIAS DIGITAIS: NOVO ESPACCO INTERATIVO NA PRODUÇÃO ESCRITA DOS SURDOS
}

\author{
Rossana Delmar de Lima Arcoverde*
}

\begin{abstract}
RESUMO: O estudo sobre o uso social da linguagem escrita/língua portuguesa por surdos em interação com ouvintes em contexto digital constitui o cerne desta pesquisa. As tecnologias digitais são potencializadoras para a instauração de interações sociais cada vez mais amplas e permitem, por meio das ferramentas de comunicação mediada por computador (e-mail, chat, lista de discussão), uma multiplicidade de dinâmicas lingüístico-discursivas que possibilitam o uso da linguagem. À luz da abordagem enunciativo-discursiva de Bakhtin e seu Círculo, analisamos situações de produção escrita de surdos e consideramos que as novas tecnologias valorizam as interaçôes verbais e inscrevem surdos e ouvintes, interlocutores plurilíngües, em um novo espaço de interação social.
\end{abstract}

Palavras-chave: Tecnologias digitais. Surdos. Interação social.

Digital TECHNOlOgies: A NEW INTERATIVE SPACE OF SOCIAL IN THE WRITTEN PRODUCTION OF THE DEAF

ABSTRACT: Studying the social use deaf people make of written language/Portuguese language when interacting with hearing people in a digital context is the core of this research. The digital technologies are a potentiating tool to implement increasingly wider social interactions and, their communication tools mediated by computer (e-mail, chat, forums of discussion) allow a multiplicity of linguisticdiscursive dynamics that permit the use of language. In the light of the enunciative-discursive approach of Bakhtin and his Circle, we analyze situations of written production by the deaf and consider that the new technologies value verbal interaction and insert both

* Doutora em Lingüística Aplicada e Estudos da Linguagem pela Pontifícia Universidade Católica de São Paulo (PUC-SP) e docente da Unidade Acadêmica de Educação da Universidade Federal de Campina Grande (UFCG).E-mail: rossanaarcoverde@uol.com.br 
Tecnologias digitais: novo espaço interativo na produção escrita dos surdos

deaf and hearing people, plurilingual interlocutors, in a new space of social interaction.

Key words: Digital technologies. The deaf. Social interaction.

\section{Introdução}

$\mathrm{O}$

crescimento vertiginoso das tecnologias digitais conquista, a cada dia, mais usuários. As tecnologias digitais são potencializadoras para a instauração de interaçóes sociais cada vez mais amplas e permitem, por meio das ferramentas de comunicação mediada por computador (e-mail, chat, lista de discussão), uma multiplicidade de dinâmicas lingüístico-discursivas que possibilitam o uso da linguagem.

A discussão sobre esse tema na área educacional requer, inicialmente, o esclarecimento sobre o público-alvo a quem se dirige, além da necessidade de se ter clareza sobre tantos outros aspectos com semelhante relevância. Por exemplo, objetivos da proposta, procedimentos metodológicos, embasamento teórico, entre outros.

Neste trabalho, elegemos os surdos como público-alvo e daí questionarmos: Para quem almejamos uma prática efetiva de uso da linguagem escrita? Como concebemos o surdo?

As respostas para essas questões só podem ser encontradas através de um percurso apaixonante e envolvente pela história de tudo que cercou e cerca os surdos e todas as questões relacionadas à surdez. Nesse caso, esse não é o momento, devido ao limite de tempo e ao objetivo do tema a ser apresentado.

Entretanto, gostaríamos de lembrar algumas passagens intrigantes sobre essa história, mas que nos servem de alerta para que não repitamos, nos dias de hoje, práticas tão excludentes.

Lane (1984), em seu livro Quando a mente ouve: a história do surdo, conta que os surdos, geralmente, na Antigüidade e na Idade Média, eram rejeitados no convívio social e considerados mal-educados e incapazes de serem educados, sendo classificados, muitas vezes, como pessoas selvagens e não civilizadas. Esses conceitos, na verdade, são atribuídos para ressaltar uma "anormalidade" em comparação com a maioria ouvinte e legitimam o estigma da deficiência. 
Essas idéias, mantidas por muito tempo, fizeram com que os surdos fossem construindo seu autoconceito. Os surdos, instaurados nas e pelas relações dialógicas com o discurso da maioria dominante, encaravam-se como doentes e, como tal, deficientes e incapazes. Adotavam, assim, a compreensão de um discurso social/ideológico dominante e acabavam representando-se pelo modo como eram vistos através dos outros.

Tudo que me diz respeito, a começar por meu nome, e que penetra em minha consciência, vem-me do mundo exterior, da boca dos outros (da mãe etc.), e me é dado com a entonação, com o tom emotivo dos valores deles. Tomo consciência de mim, originalmente, através dos outros: deles recebo a palavra, a forma e o tom que servirão para a formação original da representação que terei de mim mesmo.

(...) Assim como o corpo se forma originalmente dentro do seio (do corpo) materno, a consciência do homem desperta envolta na consciência do outro (...). (Bakhtin, 1979, p. 378)

Decorre dessas constataçōes que, nesse período, dificilmente levavase em conta o surdo como um sujeito social que, como todo ser humano, tem o direito de aprender e de ser visto como alguém que é capaz. Sendo assim, tem direito à palavra, tem direito ao uso de sua linguagem (LIBRAS, no caso do Brasil) como qualquer outro ser humano.

Todas essas discussões têm relevância direta para a formação da identidade do surdo enquanto ser humano, histórico e político. A identidade de uma pessoa é formada como parte integrante de um grupo, a partir dos contatos com grupos, pois é no meio social que ela pode encontrar modos de se auto-identificar, principalmente, pelas relações propiciadas pelo contato lingüístico. É, portanto, na história, no meio lingüístico e social em que estão envolvidos os indivíduos que a(s) identidade(s) se instaura(m) e se fortalece $(\mathrm{m})$ como tal (tais).

Ora, se esses contatos sociais não ocorrem, como o surdo vai poder instaurar suas referências de identidade? Em que lugar os surdos podem encontrar significação para sua palavra, para seu entendimento de mundo e de si mesmos?

Felizmente, a história dos homens é um contínuo social e dinâmico e, nesse movimento, podemos observar, nos tempos atuais, um olhar diferente para os surdos e para todas as questôes que dizem respeito ao seu desenvolvimento. 
Tecnologias digitais: novo espaço interativo na produção escrita dos surdos

É evidente que essa posição requer assumir uma postura que realça as potencialidades intelectuais daqueles que, mesmo sendo privados de um dos sentidos, a audição, são capazes de transpor barreiras e de encontrar novas possibilidades de interagir e de aprender. Sem dúvida, isso implica reconhecer no surdo o valor de um indivíduo, independente de seu aspecto físico, que socialmente deve ser visto como alguém que é capaz de reinventar a própria natureza e partilhar, com suas particularidades, de situações interativas, desde que lhes sejam oferecidas oportunidades para criar, comunicar e vivenciar práticas em que a diferença seja acolhida como mais uma forma de contribuição, colocando em evidência o papel que cada um possui na/para constituição de todos os seres sociais.

Essa perspectiva leva-nos a considerar que o contexto digital (Internet) é um espaço favorável que pode propiciar um novo encontro social de partilha, onde as relações de poder e autoridade são dissolvidas nos/pelos contatos virtuais. Nesse espaço não há lugar para estigmas, rotulações e preconceitos, pois, envolvidos nas tramas da Rede, somos todos participantes sociais de uma mesma comunidade, a comunidade digital, sem fronteiras, constituída pelos bits e regida sob nova forma de organização social. As oportunidades de comunicação oferecidas pelas tecnologias digitais permitem novas possibilidades de interagir e de aprender com muitos outros, diferentes e singulares, que se somam, compartilham e co-existem na imensa diversidade que institui a sociedade em rede.

\section{A linguagem escrita na vida dos surdos}

A escrita é um recurso social e suas implicações desdobram-se em um tempo histórico e cultural que determina seu valor, seu uso e seu papel na vida dos homens. Evidentemente, sem a escrita, muito do que sabemos hoje talvez não fosse possível, uma vez que toda a produção cultural da humanidade só pode ser acumulada por causa do seu registro, através de códigos variados.

É a partir do uso da escrita, como tecnologia, que conhecimentos científicos e populares são divulgados de geração a geração, propiciando a documentação e registro de idéias, de sentimentos, de informações e da história de um povo. "Sem a escrita, não há datas nem arquivos, não há listas de observações, tabelas de números, não há códigos legislativos, nem sistemas filosóficos e muito menos críticas destes sistemas" (Lévy, 1993, p. 96). 
Usar a escrita, no entanto, é muito mais do que o domínio dos códigos de um sistema lingüístico que podem ser utilizados para registrar documentos, narrativas, para publicar informaçōes, enviar bilhetes ou noticiar fatos. Escrever é fazer uso de um instrumento cultural e ideológico que permite ao sujeito refletir, elaborar o conhecimento e tomar consciência ideológica de si e do mundo que o rodeia. É, antes de tudo, fazer-se lido e ler, compreender, responder, perguntar ou argumentar. É usar uma língua, que carrega consigo valores, entoaçôes, estilos, gêneros e discursos. É, portanto, fazer uso de uma linguagem social, cultural, ideológica, política.

No caso dos surdos, essas noçōes tornam-se bastante pertinentes e oferecem suporte para mobilizar interações verbais na apropriação da linguagem (sinais e/ou escrita). Essa compreensão sugere que o enfoque se volte para práticas que privilegiem a interdiscursividade, o que implica tornar os surdos participantes ativos de uma rede enunciativo-discursiva.

A apropriação da linguagem escrita, assim, ocorrerá pelo diálogo entre as diferentes línguas sociais (língua de sinais e língua nacional), diferentes discursos, no plurilingüismo dos enunciados e na multiplicidade de vozes.

\section{A escrita e as novas tecnologias digitais}

Os recursos das novas tecnologias digitais podem, portanto, ser utilizados como instrumentos no processo de apropriação da linguagem escrita em língua portuguesa. Essas tecnologias, ao abrirem possibilidades também para novas construçôes, constituem-se num espaço de apropriação cada vez mais explorado, em especial, pelas práticas de educação a distância ou semipresencial.

Os recursos da Rede, "formas híbridas de ensino (presenciais e a distância)" (Kenski, 2001, p. 82), têm se estabelecido como um novo meio de interação, criando novas formas de trabalho. Por exemplo, é cada vez maior o número de professores que usam o e-mail, o mais simples recurso da Rede, para receber estudos, tirar dúvidas, orientar trabalhos, discutir projetos e interagir com seus alunos.

Diversos estudos (Silva, 2003; Valente, Prado \& Almeida, 2003; Collins \& Ferreira, 2004; Alves \& Nova, 2003; Arcoverde, 2004; Campos et al., 2003; Fiorentini \& Moraes, 2003) ressaltam as possibilidades 
Tecnologias digitais: novo espaço interativo na produção escrita dos surdos

de uso das tecnologias digitais nas práticas educacionais, como um suporte eficaz, para a criação de ambientes que promovem interações sociais. De um modo geral, esses estudos destacam as potencialidades dessas tecnologias pela crescente demanda de situações de ensino-aprendizagem em educação a distância, mediante propostas como "Educação a distância via Internet" (Valente, Prado \& Almeida, 2003; Martins Fontes, 2002) ou "Educação online" (Silva, 2003) que, de certo modo, incorporam "uma nova concepção de aprendizado e interatividade" (Alves \& Nova, 2003) nas diversas áreas do conhecimento.

Evidentemente, sem descuidarem de apontar as possibilidades e limitações que se instauram com o uso das tecnologias digitais, esses estudos esclarecem e reafirmam a existência de um novo meio, em que "as possibilidades de interações assíncronas e síncronas ${ }^{1}$ vão diferenciar significativamente o ensino oferecido a distância do ensino presencial mediado pelas novas tecnologias" (Kenski, 2003, p. 37).

Partindo do pressuposto de que o avanço tecnológico permite novas modalidades de comunicação, vemos que as potencialidades podem ser destacadas "pela criação de redes" que se formam, pois inscrevem definitivamente "o papel ativo dos seus participantes, os quais têm acesso a informaçōes e recursos para desenvolver atividades colaborativas, dialogar com o outro e estabelecer conexōes" (Almeida, 2003, p. 205).

A escrita, através da Internet, possibilita ao surdo escrever o português e pensar em português, fazendo uso social da linguagem escrita incorporada a uma necessidade discursiva. Nesse caso, podemos verificar que os surdos, quando vivenciam essa experiência, podem penetrar numa situação concreta de enunciação e usar a linguagem escrita em língua portuguesa para interagir com os outros.

Mediante essa nova situação de produção, é possível abrir um espaço propiciador de interaçóes e permitir que as enunciações aconteçam engendradas pela necessidade efetiva de uso da linguagem escrita. Devemos, para tanto, possibilitar, no contexto digital, condiçōes para que vozes/ enunciados se entrecruzem na configuração de um espaço onde os surdos e a palavra escrita em língua portuguesa possam se encontrar, tendo em vista que, se ao conhecimento subjaz um diálogo ativo e responsivo, sem a palavra não pode haver conhecimento.

Nessa perspectiva, o que nos interessa é criar condiçôes para que os surdos, em contexto digital e na diversidade social de linguagens, pos- 
sam interagir e, "graças ao plurilingüismo social", orquestrar seus temas, sua voz e sua linguagem. Além disso, nossa intenção é visualizar as possibilidades de uso que os recursos de comunicação mediada por computador podem ter na instauração de novas situaçôes interativas (virtuais).

As tecnologias digitais permitem aos surdos, assim como aos ouvintes, introduzirem-se, espontaneamente, na língua que estão usando para se comunicar e, inscrevendo-se numa atividade enunciativodiscursiva, ressignificar sua escrita fazendo um uso social da linguagem. Permitem que, num sentido amplo, tenham a oportunidade de interagir e aprender, independente de sua condição física.

Vejamos, então, algumas produções reveladas por meio de participações interativas de surdos-ouvintes e surdos-surdos em situação de interação verbal via tecnologias digitais, processo vivido durante nosso estudo $^{2}$ de doutorado desenvolvido na PUC-SP.

\section{Os enunciadores e seus discursos: os temas que circulam}

A língua de sinais é, para alguns, a primeira língua, que faz o surdo se reconhecer como sujeito social e enunciador efetivo, embora não haja para todos os surdos as mesmas condiçôes de acesso e desenvolvimento lingüístico. ${ }^{3}$ No entanto, o Português (no caso do Brasil) pode fazer do surdo o enunciador de seus discursos numa segunda língua (na modalidade escrita) e, assim, também se inserir como sujeito na sociedade nacional.

Fazer uso da linguagem escrita significa, para os surdos, apropriar-se de um conhecimento social e cultural de grande amplitude. Essa apropriação se dá pelo diálogo entre diferentes linguagens sociais, diferentes discursos, na pluridiscursividade de enunciados e na multiplicidade de vozes. Isso pode tornar o surdo integrante da nação a que pertence, na medida em que, ao se apropriar da linguagem escrita em língua portuguesa, ele pode estabelecer e ampliar suas interações, negociar sentidos, trocar conhecimentos, nserir-se no mundo discursivo e produzir seus próprios enunciados.

Assim, os dados mostram o discurso de um enunciador, com seus temas, entoaçôes, dialogismos e plurilingüismo, de acordo com o uso social e significativo da linguagem escrita. Nesses discursos, os "'falares' do plurilingüismo entrecruzam-se de maneira multiforme, formando novos 'falares' socialmente típicos" (Bakhtin, 1975, p. 98). Neste estudo, os surdos encontram e tomam a palavra escrita em língua portuguesa como 
Tecnologias digitais: novo espaço interativo na produção escrita dos surdos

sua e, por meio dela, não silenciam, revelando a palavra como um produto da interação social.

Os temas mais recorrentes giravam em torno das questōes sobre os surdos, a surdez, a profissionalização do intérprete da LIBRAS, o preconceito, o conflito que existe entre a família e o uso dessa língua, temas do diaa-dia e de atividades que eles gostam de fazer, como mergulho e conexão na Rede. Esses temas envolveram surdos e ouvintes numa interação verbal efetiva e, na maioria das vezes, eram os surdos que traziam à tona os temas em pauta.

É possível notar que as interlocuções revelam surdos com experiências de vida e consciência de seu papel de ajudar outros surdos, o que perpassa, sem dúvida, o conhecimento, o uso e a valorização da língua de sinais. Vejamos alguns exemplos: ${ }^{4}$

\section{Exemplo 1: LIBRAS 5}

From: Paullo
To: roteiros@lists.lael.pucsp.br
Sent: Tuesday, April 22, 2003 4:59 PM
Subject: [Roteiros] sou eu?!
Tenho mais ou menos 200 meus amigos surdos, pois não sou oralista, só uso Libras
para dar alegre, unir mais amigos surdos para comunicar muito gostoso.
Acho que Libras é muito importante, porque meus pais nao me explica direito das
noticias, porisso nao deu desenvolvimento, entao, eu e meu irmao sempre usamos Libras
para entender perfeitamente, porisso eu ajudo de ensinar todos surdos sobre noticias
que conseguem entender.

From: Johnn

To: roteiros@lists.lael.pucsp.br

Sent: Tuesday, May 20, 2003 11:26 AM

Subject: [Roteiros] Re: Oi, Pessoal

A vida de uma pessoa surda e muito difícil, o estudo então mais ainda professores tinham problema comunicação, é difícil surdo na escola Conselho Pinheiro. Eu tinha 8 anos de idade não sabia nada de língua de sinais, só que conhecei surdo que sabia e eu tinha muita vontade de aprender língua de sinais, porque sem saber os sinais ficava muito de difícil aprendi o português, hoje eu entendi o surdo que sabe sinais aprende mais rápido se desenvolvi e não repito o ano e fica mais fácil para encara sala de aula comum. 
O contexto social em que os surdos se envolveram ofereceu a oportunidade de se comunicarem pela linguagem escrita, sem perderem a identidade, procurando se representar na mensagem escrita e mostrando que "a palavra está sempre carregada de um conteúdo ou de um sentido ideológico ou vivencial" (Bakhtin \& Volochinov, 1929, p. 95).

Em alguns episódios, evidenciam-se práticas discursivas em que a linguagem escrita em língua portuguesa foi utilizada para discutir posiçōes, revisar concepções e assinalar manifestaçōes entrelaçadas por conteúdos ideológicos sobre aspectos relacionados à condição de ser surdo ou ao uso da língua de sinais, pois "cada palavra se apresenta como uma arena em miniatura onde se entrecruzam e lutam os valores sociais de orientaçáo contraditória" (idem, ibid., p. 66).

Desde o início do uso da lista de discussão, notamos o engajamento dos surdos nas interaçôes. Algumas mensagens realçavam aspectos importantes vividos por eles, e nada mais apropriado do que compor esse novo espaço com os problemas e os conflitos que os acompanhavam, demonstrando a possibilidade de que o contexto digital seja uma expansão da realidade. Assim, Paullo envia a mensagem e levanta uma discussão sobre um conflito que parece comum para alguns surdos. No caso específico dessa mensagem, o amigo a quem ele se refere é Dudu, que, de imediato, responde ao e-mail.

Exemplo 2: O conflito família $x \operatorname{LIBRAS}^{6}$

\section{De: Paullo}

Enviada em: Sexta-feira, 25 de Abril de 2003 9:30

Para: roteiros@lists.lael.pucsp.br

Assunto: Re: [Roteiros] sou eu ?!

Tenho meu amigo oralista que estava depressão normal, depois família dele não gostou que ele começou de aprender Libras, gostou mesmo para conversar gostoso de usar libras com surdos igualzinho remédio para dar boa saúde, MAS família dele não deixa com força ele para usar de libras, agora está muito forte depressão ...

Se entendermos que, para o desenvolvimento da linguagem, a família constitui a base das primeiras interações e que, a partir dela, recebemos os valores sociais e culturais que nos constituem, a privação do uso da lín- 
Tecnologias digitais: novo espaço interativo na produção escrita dos surdos

gua de sinais é a negação das possibilidades de se ser o que se é. As razões que levam a família a excluir a língua de sinais da vida de um surdo podem ser várias e, muitas vezes, validam atributos preconceituosos revestidos pelo desprestígio social que perpassa o uso da língua de sinais.

No entanto, constatamos as forças sociais que criam a vida da linguagem. Assim, enquanto a família assume uma prática em que impóe o apagamento de uma língua social, o surdo busca, no contato com outros surdos, a linguagem viva, revelando a força que há em meio a um plurilingüismo dinâmico, que faz a língua manter-se sempre presente e em contato com outras linguagens.

Nessa dinâmica que mantém a vida das linguagens sociais, há duas forças, centrípetas e centrífugas, que atuam para a centralização de uma língua nacional e para a descentralização que dispersa e permite outras linguagens, pois "ao lado das forças centrípetas caminha o trabalho contínuo das forças centrífugas da língua" (Bakhtin, 1975, p. 82).

Com base nessa concepção, podemos entender o que ocorre com Dudu, que, apesar de viver o conflito entre a exigência da família (oralizar) e a necessidade de vivenciar a língua de sinais, encontra a saída para seu problema criando para si um enfoque "bilíngüe", de acordo com sua realidade e, por isso, defende que é preciso "saber como falar como oralismo e tbém é legal aprender e falar com as mãos (LIBRAS)" (Dudu), mediante o contato com outros surdos, que o leva a manter suas relaçôes de amizades, sem se indispor com a família.

\section{Exemplo 3:}

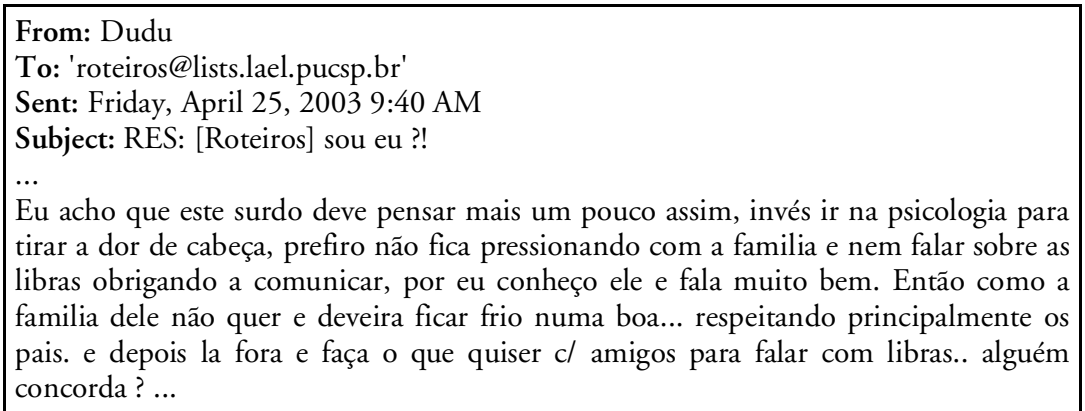


É importante ressaltar que, na nossa realidade, há uma diversidade de surdos que vivem diferentes situações e condições sociais em que foram educados e em que construíram, ao longo do tempo, uma visão sobre si mesmos e sobre sua surdez, de acordo com cada momento histórico. Talvez por isso, Dudu tenha encontrado a melhor opção para sua vida, tendo incorporado o discurso ideológico, histórico e cultural que o constituiu. Nesse sentido, ele diz: “... lembre-se sempre é recomendável a usar duas linguas (Fala + Mãos)" (Dudu). Afinal de contas, como afirma Bakhtin (1979, p. 378), "Tudo o que me diz respeito, a começar pelo meu nome, e que penetra em minha consciência, vem-me do mundo exterior, da boca dos outros (da mãe, etc.), e me é dado com a entonação, com o tom emotivo dos valores deles".

Diversos outros temas surgiram e acabavam voltando para questōes específicas do grupo em foco. Desse modo, quando eles buscavam a aproximação pessoal, sempre traziam questôes curiosas sobre a surdez de cada um, como se estivessem estreitando os laços que os uniam no contexto do trabalho.

Em meio a uma dessas interações verbais sobre o uso da LIBRAS, Dudu sempre surgia com uma pergunta que ampliava a discussão ou levava para outros contextos. A mensagem do Exemplo 4 foi uma resposta para Roxane e integrava uma discussão que estava acontecendo sobre o uso da LIBRAS. As palavras de Dudu revelam a clara noção que ele tem sobre a possibilidade de aprender uma linguagem, através de uma prática social efetiva, em que formas de interações verbais sejam mantidas e privilegiadas em diferentes contextos.

No final da mensagem, Dudu traz uma outra questão que desencadeia vários outros enunciados e que não só instiga enunciados de outros participantes, como também promove uma ampliação da interação e o enriquecimento do tema, que só é possível porque "cada enunciado é um elo da cadeia muito complexa de outros enunciados" (Bakhtin, 1979, p. 291).

Essa cadeia de enunciados é um exemplo do quanto foi possível interagir por meio do uso da lista. Cada um com suas observaçôes, com seus valores, suas afinidades e entonaçôes que, no interior das trocas enunciativas, ganham sentido, tendo em vista que "a relação dialógica é uma relação (de sentido) que se estabelece entre enunciados na comunicação verbal" (idem, ibid., p. 345). Os enunciados mantêm a relação dialógica que ressoa a partir da compreensão do enunciado do 
Tecnologias digitais: novo espaço interativo na produção escrita dos surdos

outro, emergindo pela possibilidade de se atribuir sentido aos enunciados com que se defrontaram.

\title{
Exemplo 4: ${ }^{7}$
}

From: Dudu

To: 'roteiros@lists.lael.pucsp.br'

Sent: Friday, April 25, 2003 5:53 PM

Subject: RES: RES: [Roteiros] link

É fácil, você tem que atrás dos surdos para conversar, passear e acaba aprendendo a falar com libras, e capaz não precisa fazer o curso pago, concorda...! Gosta de mergulhar?

\author{
De: Roxane \\ Enviada em: Sábado, 26 de Abril de 2003 8:58 \\ Para: roteiros@lists.lael.pucsp.br \\ Assunto: Re: RES: RES: [Roteiros] link \\ Eu? Não sei nem nadar direito! \\ Onde você mergulha? \\ Roxane
}

\begin{tabular}{l}
\hline From: Dudu \\
To: 'roteiros@lists.lael.pucsp.br' \\
Sent: Monday, April 28, 2003 7:07 AM \\
Subject: RES: RES: RES: [Roteiros] link \\
\\
Olá Roxane, bom dia! \\
Como foi este final de semana ? Espero que ocorreu tudo bem. \\
No mergulho é saber pelo menos nadar, por que faz parte mais importante saber usar \\
o sistema de respiratório para evitar o risco. Sabendo-se, este mergulho é usado para os \\
equipamentos em nitrogencio 79\% e oxigenio 21\% vem dentro no cilindro onde \\
pode respirar dentro na agua. É muito divertido e inesquecível! \\
Mergulhei na última vez foi em Ilha Grande-RH, uma delas dos peixes que eu vi era \\
uma tartaruga que media 1,2 metros...! Muito legal mesmo! Tbém vc pode ver \\
mergulhar em naufragios.... e se quiser entrar a historia dos naufragios é só passar \\
acesso com endereço www.naufragiosdobrasil.com.br \\
Beijs \\
Dudu
\end{tabular}




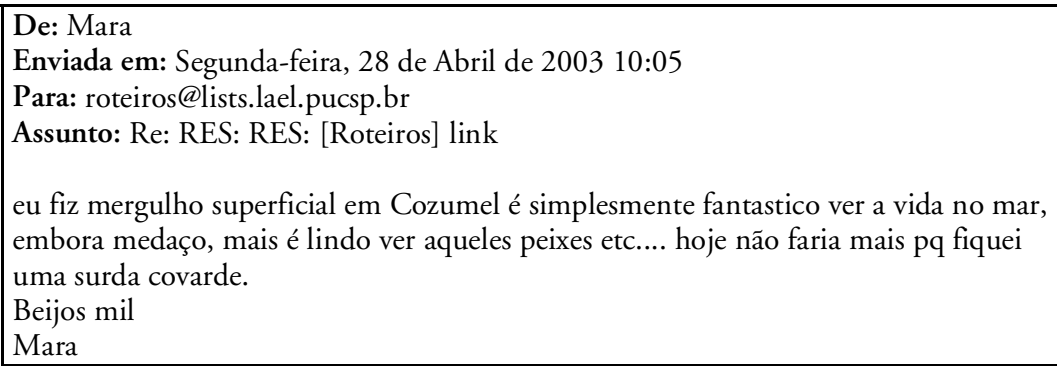

De: Rossana

Enviada em: Segunda-feira, 28 de Abril de 2003 10:32

Para: roteiros@lists.lael.pucsp.br

Assunto: Re: RES: RES: [Roteiros] link

e?!! então eu sempre fui uma ouvinte covarde, pois morro de medo desse negócio de ficar no meio de muita água. Imagine lá no fundo do mar :000 Nem pensar...

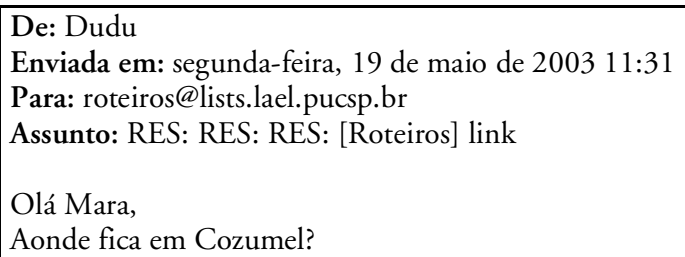

Tem razão Markham (1998), quando fala do sentido de presença que temos quando estamos online, já que, nesse período, podemos vivenciar e compartilhar um pouco de cada um, suas angústias e suas necessidades. Não há dúvida de que isso ocorreu em dupla mão. Surdos e ouvintes, algumas vezes, enviaram mensagens comentando sobre o trabalho, desejando sucesso, pois mesmo "do lado de lá", distantes por um cabo de fibra ótica ou uma linha telefônica, eles permaneceram do "lado de cá" e puderam vivenciar, também, as nossas ansiedades.

O contexto digital constituiu um lugar de encontros, de parcerias que foram fundamentais para o entrelaçamento dos ciberenunciados, que contribuíram para elucidar a Rede como uma esfera comunicativa de 
Tecnologias digitais: novo espaço interativo na produção escrita dos surdos

grupos sociais que concretizam a esfera digital. Um olhar sobre as ocorrências sustenta a tese de que, no contexto social, as interações envolveram surdos no uso da linguagem escrita em língua portuguesa.

No caso dos surdos, essa prática passa, incondicionalmente, pelas interações que eles podem construir e compartilhar com os ouvintes. Por essa razão, é preciso que os ouvintes participem como interlocutores interativos e dedicados à partilha das linguagens sociais que devem estar em relação dialógica permanente.

A análise das produçôes escritas dos surdos assinala que a interação vivida no contexto digital é um caminho que deve ser tecido pouco a pouco, dia a dia, byte a byte e que pode constituir surdos e ouvintes em interlocutores efetivos que compartilham experiências, conhecimentos e linguagens sociais. As conexões estabelecidas formam os fios dialógicos e ideológicos necessários para o encontro plurilíngüe de enunciados, de vozes, de entonaçōes, de temas e de pontos de vista, abrindo-se, assim, novo espaço de interação social para o surdo.

Enfim, pudemos constatar que é possível, por meio das ferramentas de comunicação mediada por computador, a despeito de todas as dificuldades técnicas, oportunizar situaçōes em que práticas enunciativodiscursivas aconteçam (Arcoverde, 2004). Desse modo, poderemos promover, para os surdos, situaçôes de uso social da linguagem escrita em língua portuguesa.

\section{Considerações finais}

As relações concretizadas no contexto digital conferem às interações um importante papel no uso social da linguagem escrita em língua portuguesa, principalmente no caso dos surdos. Imersos nesse contexto, surdos e ouvintes dialogizam a própria língua, "fundindo dois enunciados potenciais como que duas réplicas de um possível diálogo" (Bakhtin, 1975 , p. 158).

No entanto, o trabalho no contexto digital requer muito mais do que simplesmente abrir um espaço e oferecer oportunidades para escrever. Ainda há muito para ser refletido, o que nos remete a uma "encruzilhada". Deve levar um tempo até decidirmos qual o caminho que devemos seguir e que, evidentemente, não será fácil de percorrer, seja qual for a trilha que tenhamos de escolher. 
Esse encontro abre a perspectiva para o uso da linguagem escrita, que: (a) é priorizada no potencial da Rede como um suporte à comunicação; (b) valoriza as relaçôes do cotidiano, permitindo que pessoas se revelem, criem novas possibilidades e mostrem o que sentem, suas ansiedades, suas inquietaçōes; (c) pode configurar o ponto de partida para práticas discursivas efetivas na criação de situações de ensino-aprendizagem da linguagem escrita em língua portuguesa.

Tecnologias colaborativas permitem a construção de formas comuns de ver, agir e conhecer, ou seja, são ferramentas que habilitam indivíduos a se engajarem conjuntamente na atividade de produção de conhecimento compartilhado. (Campos et al., 2003, p. 64)

Evidentemente, as tecnologias digitais têm seu lado positivo e negativo. Por si só, elas não são suficientes para solucionar problemas educacionais e sociais tão abrangentes e historicamente constituídos. Isso nos parece inquestionável. Por outro lado, não tínhamos a ambição de resolvê-los.

Nosso intento, entre outros, é o de encorajar práticas que promovam situações interativas e que possam agregar valores e condiçôes sociais para futuras aprendizagens, dada a crescente disseminação de usos das tecnologias digitais na área educacional.

As possibilidades de um novo fazer pedagógico com os avanços da tecnologia são alentadoras. Alternativas existem e, para isso, devemos investir em pesquisas, no sentido de buscar meios eficazes para vencer os desafios e limitaçôes que elas nos impōem. Nas tecnologias há interatividade, mas as interaçốes são decorrentes dos laços sociais que criamos com todos os outros que participam ativamente das situaçóes significativas que oferecemos.

Com efeito, por meio delas, vivenciamos novas experiências, novas práticas que desvelaram novas atitudes, que, dependentes dos vínculos sociais estabelecidos, podem vislumbrar inovaçôes pedagógicas propulsoras de situações efetivas de ensino-aprendizagem.

Ainda há muitos confrontos e debates. Entre eles, o acesso democrático às tecnologias digitais é palco de fervorosas discussões em diversos campos científicos e políticos. Cabe, então, permanecer na luta e encontrar o uso profícuo que as tecnologias ensejam, pois, apesar de todas as adversidades sociais e culturais existentes, elas constituem um novo espaço de interação social na produção escrita dos surdos.

Recebido em outubro de 2005 e aprovado em fevereiro de 2006. 
Tecnologias digitais: novo espaço interativo na produção escrita dos surdos

\section{Notas}

1. Nas interações síncronas os aprendizes estão online e podem comunicar-se, por exemplo, através de chats, videoconferência. Nas assíncronas, a comunicação ocorre de acordo com o tempo de cada aprendiz. Por exemplo, são interações efetuadas através do uso de e-mail ou listas de discussão.

2. O estudo "Os surdos em contexto digital: o encontro com a palavra escrita em língua portuguesa" foi desenvolvido de 2000 a 2004, no Programa Pós-graduado em Lingüística Aplicada e Estudos da Linguagem (LAel/PUC-SP), sob a orientação da Profa Dra Roxane Rojo.

3. Em alguns casos, há um acesso tardio à língua de sinais, fazendo surgir a produção de combinações de "uma comunicação gestual caseira utilizada para fins de satisfação de necessidades e relatos de acontecimentos familiares" (Lodi, Harrison \& Campos, 2002, p. 37).

4. Os participantes autorizaram o uso dos nomes próprios no estudo.

5. Ênfase em itálico adicionada.

6. Ênfase em itálico adicionada.

7. Ênfase em itálico adicionada.

\section{Referências bibliográficas}

ALMEIDA, M.E.B. Educação, ambientes virtuais e interatividade. In: SiLVA, M. (Org.) Educação online: teorias, práticas, legislação, formação corporativa. São Paulo: Loyola, 2003. p. 201-215.

ALVES, L.; NOVA, C. (Org.). Educaçãa a distância: uma nova concepção de aprendizado e interatividade. São Paulo: Futura, 2003.

ARCOVERDE, R.D.L. Os surdos em contexto digital: o encontro com a palavra escrita em língua portuguesa. 2004. Tese (Doutorado) - Programa de Estudos Pós-Graduados em Lingüística Aplicada e Estudos da Linguagem, Pontifícia Universidade Católica de São Paulo, São Paulo.

BAKTIN, M. Questōes de literatura e de estética: a teoria do romance. São Paulo: HUCITEC; UNESP, 1975.

BAKTIN, M. Estética da criação verbal. São Paulo: Martins Fontes, 1979.

BAKHTIN, M.; VOLOCHINOV, V.N. Marxismo e filosofia da linguagem. São Paulo: HUCITEC, 1929.

CAMPOS, F.C.A. et al. Cooperação e aprendizagem online. Rio de Janeiro: DP\&A, 2003. 
COLLINS, H.; FERREIRA, A. (Org.). Relato de experiências: línguas na Internet. Campinas: Mercado de Letras, 2004.

FIORENTINI, L.M.R.; MORAES, R.A. (Org.). Linguagens e interatividade na educação a distância. Rio de Janeiro: DP\&A, 2003.

KENSKI, V.M. Em direção a uma ação docente mediada pelas tecnologias digitais. In: BARRETO, R.G. (Org.). Tecnologias educacionais e educação a distância: avaliando políticas e práticas. Rio de Janeiro: Quartet, 2001. p. 74-84.

KENSKI, V.M. Novas tecnologias na educação presencial e a distância. In: Alves, L.; Nova, C. (Org.). Educação a distância: uma nova concepção de aprendizado e interatividade. São Paulo: Futura, 2003. p. 25-42.

LANE, H. When the mind hears: a history of the deaf. New York: Random, 1984.

LÉVY, P. As tecnologias da inteligência: o futuro do pensamento na era da informática. Rio de Janeiro: Editora 34, 1993.

LODI, A.C.B.; HARRISON, K.M.P.; CAMPOS, S.R.L. Letramento e surdez: um olhar sobre as particularidades dentro do contexto educacional. In: Lodi, A.C.B. et al. (Org.). Letramento e minorias. Porto Alegre: Mediação, 2002. p. 35-46.

MARKHAM, A. Life online: researching real experiences in virtual space. Walnut Creek, CA: Altamira, 1998.

MARTINS FONTES, M.C. Aprendizagem de inglês via Internet: descobrindo as potencialidades do meio digital. 2002. Tese (Doutorado) Programa de Estudos Pós-Graduados em Lingüística Aplicada e Estudos da Linguagem, Pontifícia Universidade Católica de São Paulo, São Paulo.

SILVA, M. (Org.). Educação online: teorias, práticas, legislação, formação corporativa. São Paulo: Loyola, 2003.

VALENTE, J. A.; PRADO, M.E.B.B.; ALMEIDA, M.E.B. (Org.). Educação a distância via Internet. São Paulo: AVERCAMP, 2003. 